\section{COMMUNICATING DEAF THEORY: A DATA DRIVEN APPROACH}

Benjamin Bahan

Matthew Malzkuhn

Gallaudet University

NOVEMBER I, 2018 


\section{A CALL}

... TO FORMULATE DEAF THEORY

- "...theory is a well-substantiated explanation of some aspect of the natural world, based on a body of facts that have been repeatedly confirmed through observation and experiment. Such factsupported theories are not "guesses" but reliable accounts of the real world."

- American Association for the Advancement of Science

- "THE RIGHT WAY TO DEVELOP THEORY IS TO COLLECT DATA THEN MAKE THEORY FROM DATA (SLOBIN 2006)" 


\section{WHAT DOES OUR DATA SAY ABOUT US?}


- National and Global Advocacy and Activism

- Pedagogy and Medicine

\section{*DATA FROM DEAF LIVES}

- Technologies

- Arts, literature and life stories

- Utopia and Superheroes 

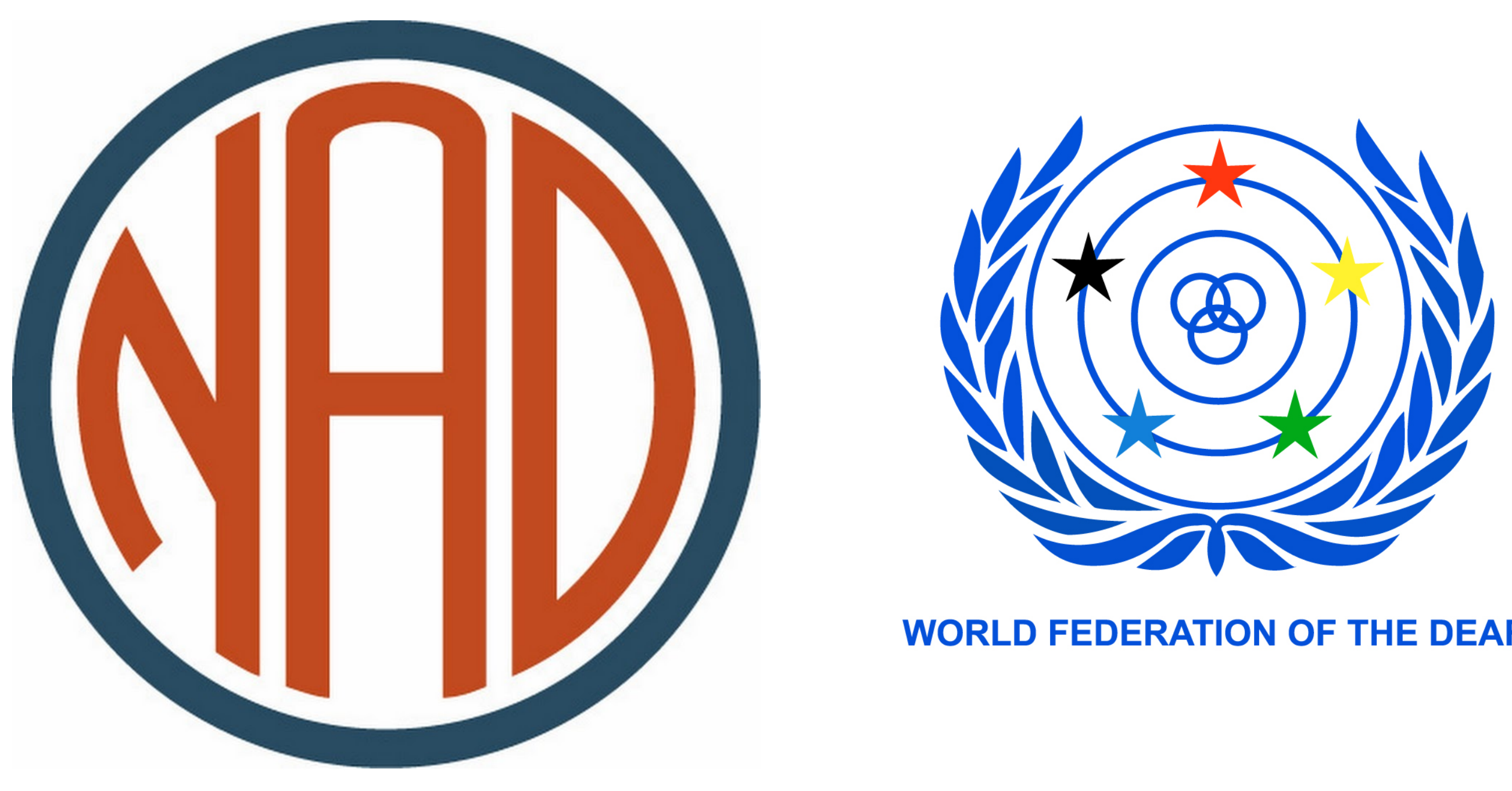

WORLD FEDERATION OF THE DEAF 


\section{NAD 2020 VISION}

\section{- Language}

We believe it is the right of every deaf and hard of hearing person to acquire and express themselves in American Sign Language and English.

\section{- Attitude}

We must change the society's perception of people who use ASL to one that recognizes us as a unique community with our own language and culture.

\section{- Self-Determination}

We believe that society must accept our organization as an integral part in any decision-making process that influences any deaf and hard of hearing person.

\section{- Management}

We are committed to responsible resource allocation through optimal use of our people, time, and money in the pursuit of our mission, vision, and values. 


\section{NAD PRIORITIES \\ [SOME SELECTED ONES]}

\section{8-2010}

Captioning in Movie Theaters

Certified Deaf Interpreters

- Protect State Deaf Schools

Federal Recognition of ASL

- ASL as a Deaf Child's Human Right

- National Agenda for Mental Health

- Bilingual-Bicultural Emphasis in Deaf Education

- Early Intervention and Parent Education

- Preservation of American Deaf History and ASL

- Removal of Department of Transportation Requirement

\section{2-2014}

Establishment of an Employment Task Force.

- National Leadership Training Program

- Mental Health Services

- Legislative Training

- Expand Captioning Access

- Education/EHDI

- National ASL Content Standards

\section{I4-2016}

- Preservation and Advocacy of Relay Services (PARS)

- Preservation of Mental Health Services that Meet the Needs of Deaf People

- Defining and Supporting the Education Strategy Team's Focus for 2014-2016

- Outreach to DeafYouth including Mainstream School Students

\section{6-2018}

- National Employment Resource Center

- Enhance NAD Information Clearinghouse and Communications Strategy

- Child Protective Services and Best Practices with Respect to Language/Culture

- Campaign to End Language and Cultural Deprivation

- Creation of Mental Health Training Program and a Communication Hub on Health Related Information 
- Vision: Human rights for deaf people including recognition of sign language in all aspects of life

- Mission:WFD works for the realisation of deaf people's human rights in partnership with the United Nations and its agencies, national organisations of deaf people, and relevant stakeholders 


\section{WFD POSITION PAPERS AND STATEMENTS [SOME SELECTED ONES]}

\section{Role of WFD}

- Improve the status of national sign languages

- Better education for Deaf people

- Improve access to information and services

- Improve human rights for Deaf people in developing countries
- 2007 Statement on the Unification of Sign Languages

- 2009 Statement on Unification of Arab Sign Languages

- 2013 Statement on DeafWomen and Girls not able to Enjoy Basic Human Rights

- 2014 Statement on Sign Language Work Statement on Standardized Sign Language

- 2015 Discussion on the Right to Education of Persons with Disabilities

- 2016 Statement on Deaf People's Right to Drive a Car or other Vehicles

Position Paper on the Language Rights of Deaf Children

- 2017 Statement on the Adoption and Adaptation of Technologies and Accessibility

- 2018 Statement on Use of Signing Avatars

- 2018 Position Paper on Deaf Community as linguistic Identity or Disability

- 20 I8 Position Paper on Inclusive Education 
- Sign Language Rights as Human Rights

- Access to Information

\section{COMMONALITIES}

- Quality of Access

- Technical Access and Accommodations

- Bilingual Education

- Removing Discrimination 


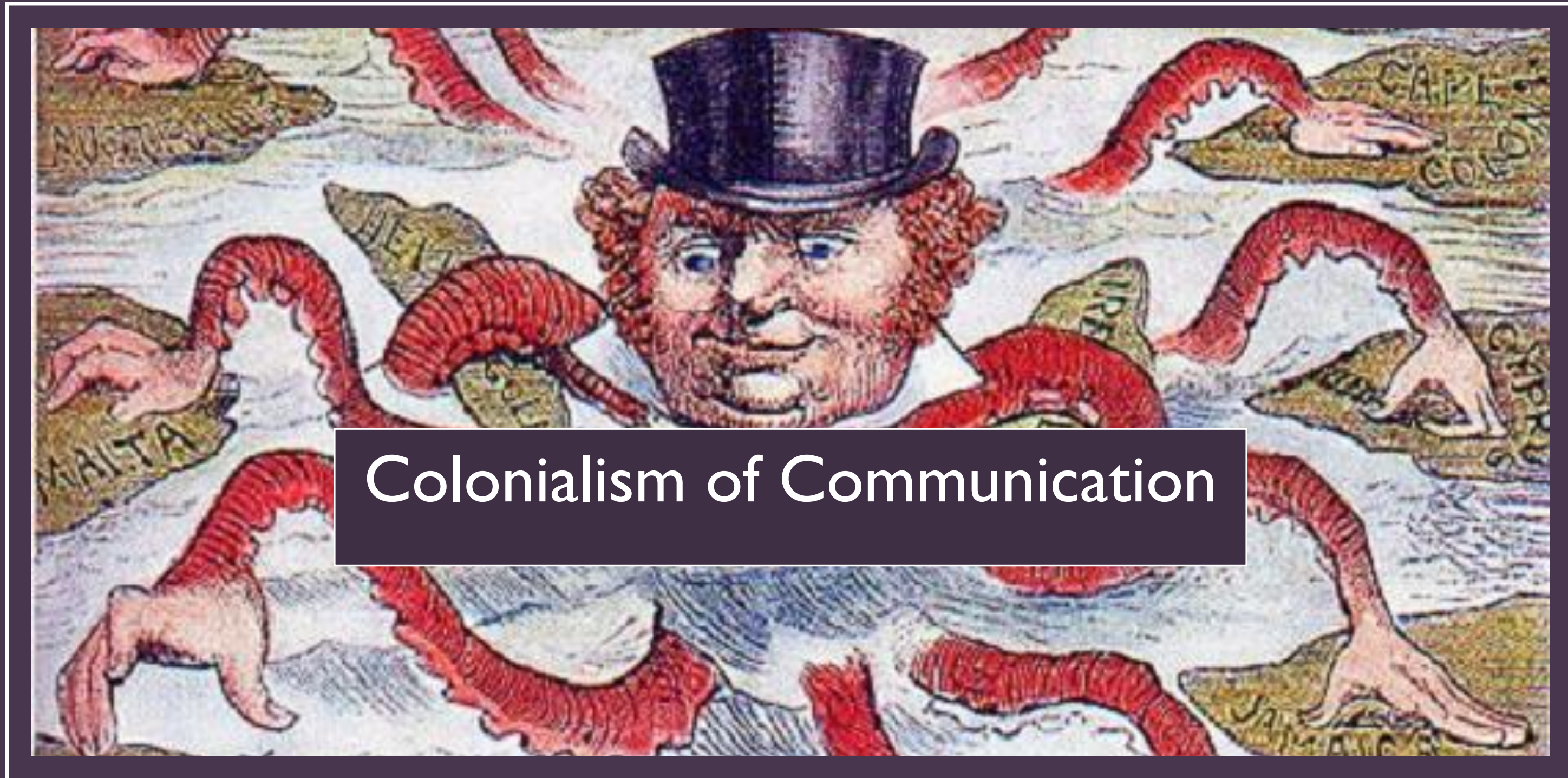




\section{PEDAGOGY AND MEDICINE}

- History of pedagogical and medical practices

- Revolves around making speech possible (education) and accessible (medical)

- Impact on Deaf Lives (life history)

- Sign Language as Communication Disorder

- National Institute on Deafness and Other Communication Disorders

- Many ASL programs are housed in departments of:

- Speech and Language

- Communication Disorders

- Special Education

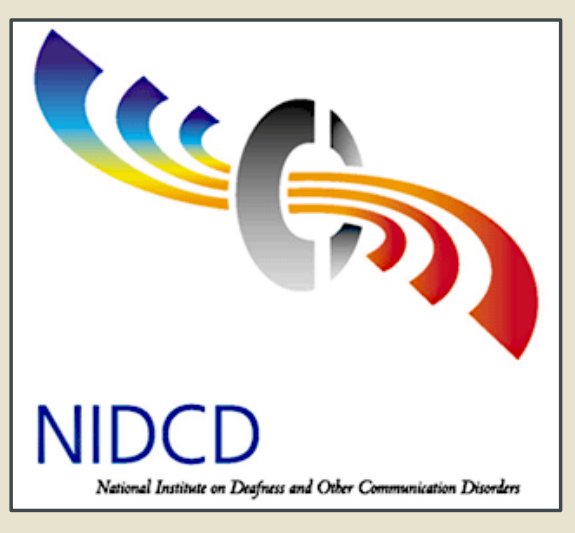


COMMUNICATION TECHNOLOGIES

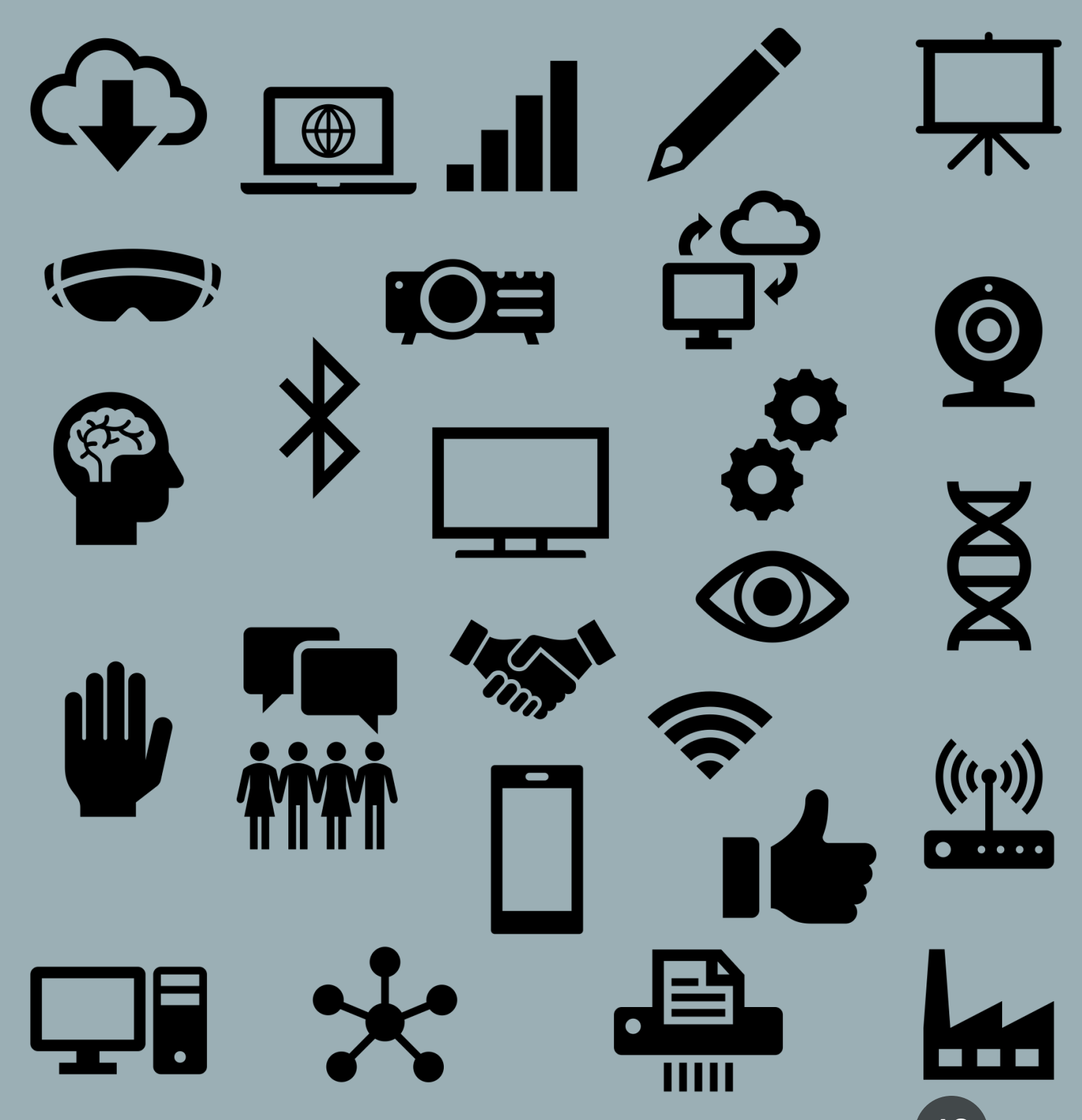




\section{COMMUNICATION ENGINEERING}

Cordano, 2017

- Communication Technologies Developed by Others for Us

- Hearing devices to "assist" us in listening

- Communication Technologies Engineered/Hacked by Us for Us

- Hacking other senses (sensory extensions)

- Doorbells, baby crier, alarm clock, etc.

- TTY, Videophone, text messaging

- Hilde Haualand -T Mobile 2007

- Next generation-ML2,TAP, Motion Savvy, and others

- Deaf Expo-booths are predominantly communication related from relay services to electronic devices. 


\section{ARTS, LITERATURE \& LIFE HISTORIES}


Mother Tongue

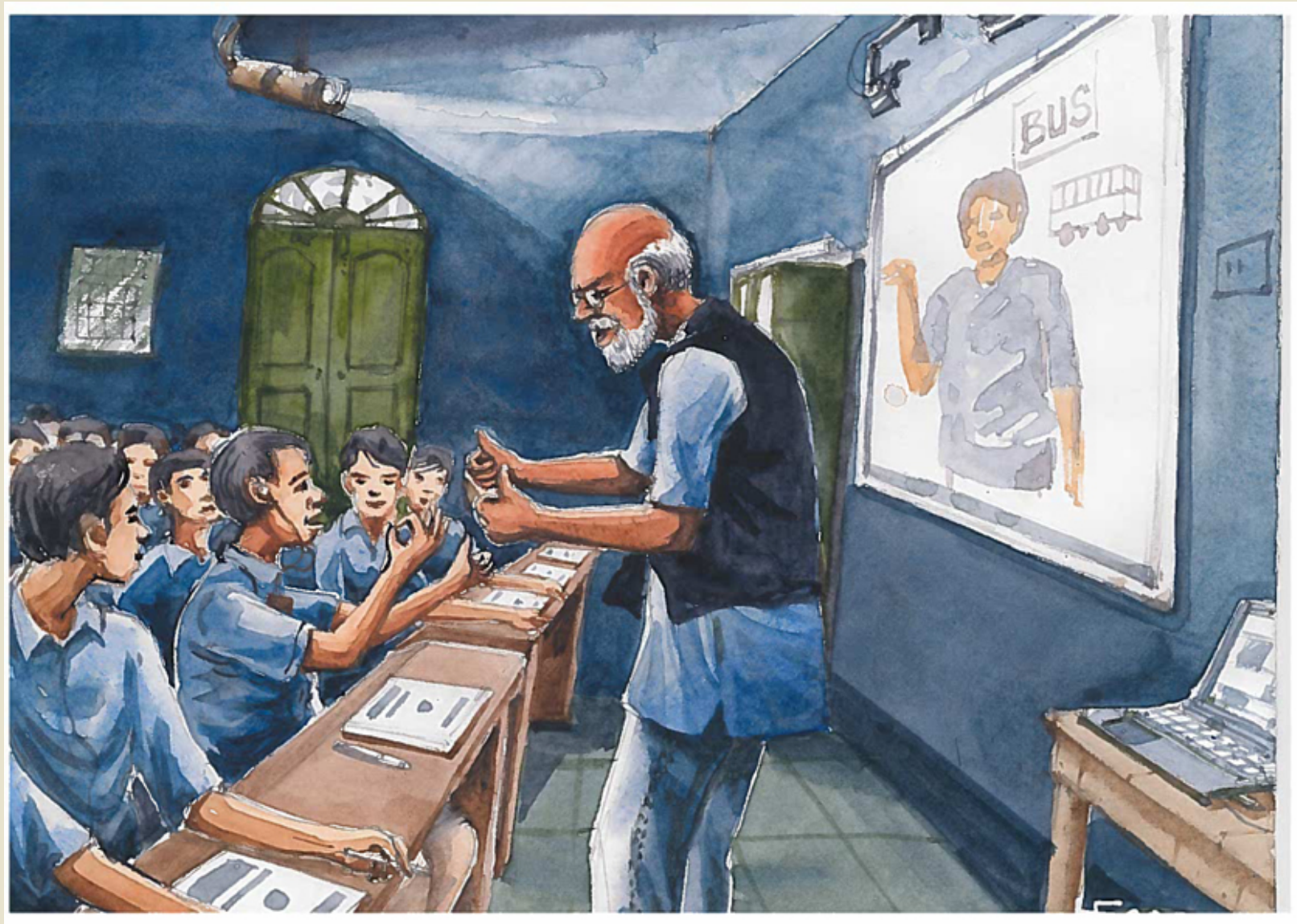

Master Swastik Jana • Age: 16

Country: India
Mechanical Ear

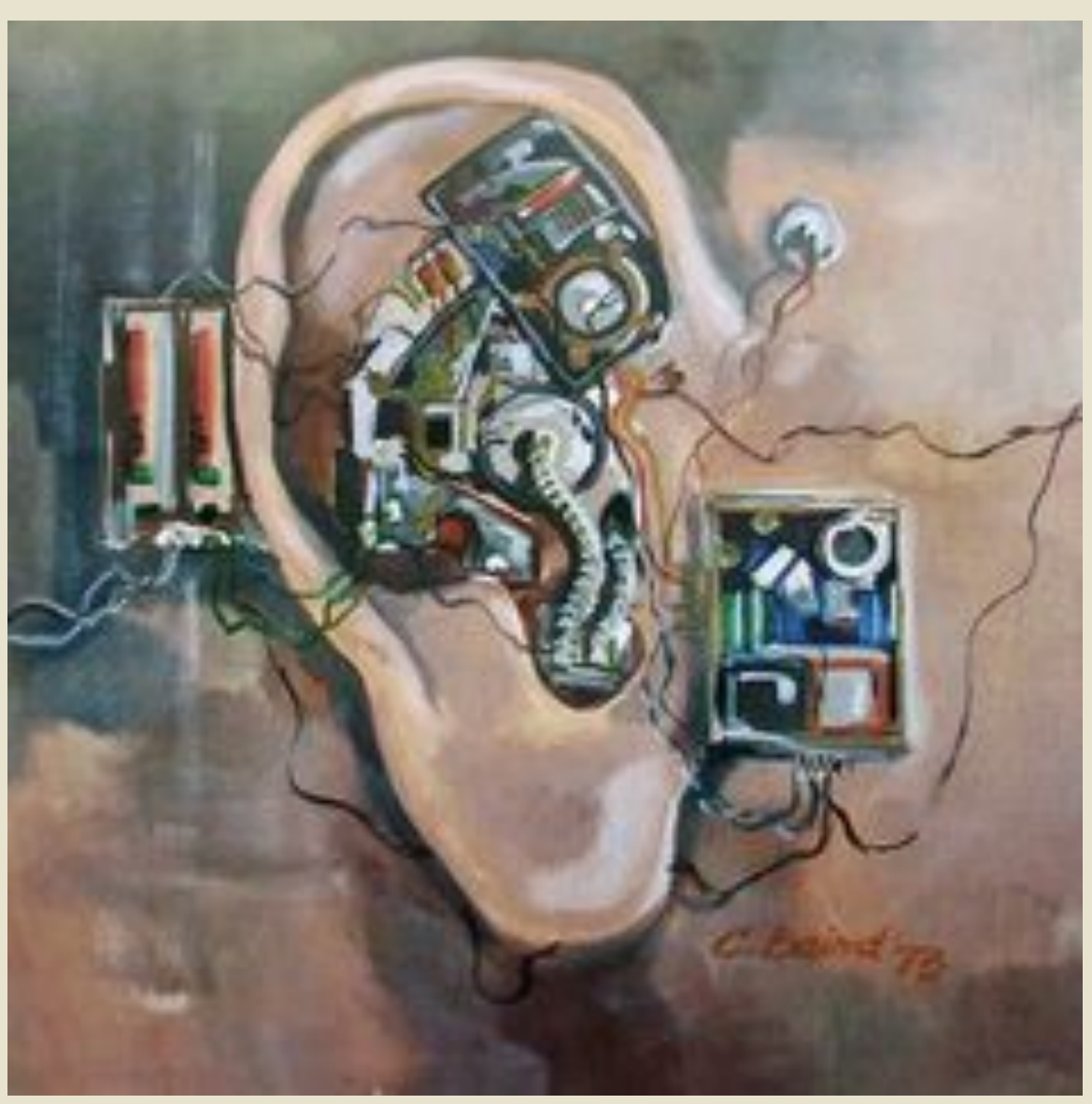

Chuck Baird

Country: USA 


\begin{tabular}{cc|}
\hline $\begin{array}{c}\text { Resistance } \\
\text { De'VIA }\end{array}$ & $\begin{array}{c}\text { Affirmation } \\
\text { De'VIA }\end{array}$ \\
\hline Audism & Empowerment \\
Oralism & ASL \\
Mainstreaming & Affiliation \\
Cochlear Implant & Acculturation \\
\hline $\begin{array}{c}\text { Identity } \\
\text { Confusion }\end{array}$ & Acceptance \\
\hline Eugenics & Deafhood \\
\hline
\end{tabular}




\section{LITERATURE: NARRATIVES}

Bahan (2006) "Making sense of ASL Literature"

- Over 500 Narratives (mostly focus on NPEs and Deaf Folklores plus a few fiction base on deaf lives)

- The taxonomy of the narratives funneled down into three general themes:

I. Communication and Language Values

2. Dealing with Ignorance and Discrimination

3. Sensory Orientation and Sensory Worlds

- Motifs (refer to sensory worlds)

- Doors

- Windows 


\section{LITERATURE: POETRY}

\section{Dorothy Miles}

- Communication \& Language Values

- Language for the Eye

- The Gesture

- Defiance

- Total Communication

- To a Deaf Child

- Dealing with Discrimination

- Elephant Dance

- Sensory Orientation/Worlds

- The Skunk

\section{Joseph Castronovo}

- Communication \& Language Values

- Paris' Silent Sleep

\section{Ella Mae Lentz}

- Communication \& Language Values

- The Treasure

- Sign is like a Tree

- Travels with Malz

- The Door

- To a Hearing Mother

- Silence oh Painful

- The Dogs

- Children's Garden

- Dealing with Discrimination

- Baseball Game

- Sensory Orientation/Worlds

- Eye Music 


\section{LITERATURE: POETRY}

Patrick Graybill

- Communication \& Language Values

- Distant Call

- Paradox

- Defiance

- Total Communication

- To a Deaf Child

- Dealing with Discrimination

- Elephant Dance

- Sensory Orientation/Worlds

- The Skunk

\section{Clayton Valli}

- Communication \& Language Values

- The Cave

- Dandelions

- Snowflake

- DeafWorld

- Hands Folded

- Sit and Smile

- Dealing with Discrimination

- Lone Sturdy Tree

- I'm Sorry

- Sensory Orientation/Worlds

- Hands 


\section{LIFE STORIES}

- Deaf Life Stories (Bahan and Bauman data collected 200 I-2006)

- Feeling at home where communication happens

- Unsigned home $=$ excommunicated $=$ unhomed

- Deaf Journeys - often to the site of communication

- To hearing neighbors who can communicate or play sports

- To extended families who sign because communication is accessible

- To deaf friends because communication is maximized

- To deaf places, spaces

- Deprivation leads to increased desire to adhere to one another

- Value of being with one another 
Aquarius

Activities: JrCAD 3; Clerc Dorm Secretary 3; In

Raffle Committee Chairperson 4; Volley bar

Hobbies: Joking and talking with friends

Favorite Saying: "Finish making after graduation

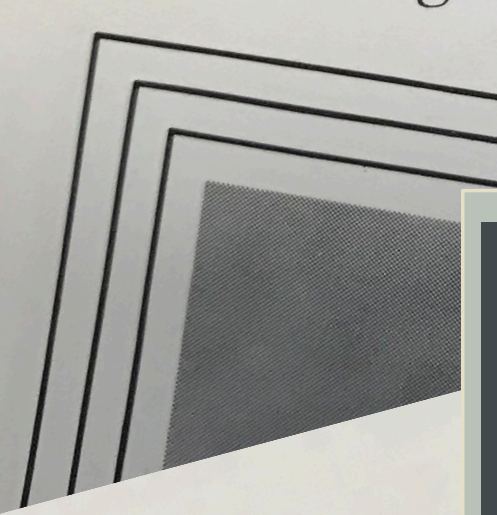

DEAF SCHOOL YEAR BOOK

Scorpio

Carlos

Activities: Track 1; Basketball 1.

Hobbies: Visiting friends.

Plans to work after graduation.

Favorite Saying: "Tough"

pisces

Hobbies: Basketball, movies and going out with friends.

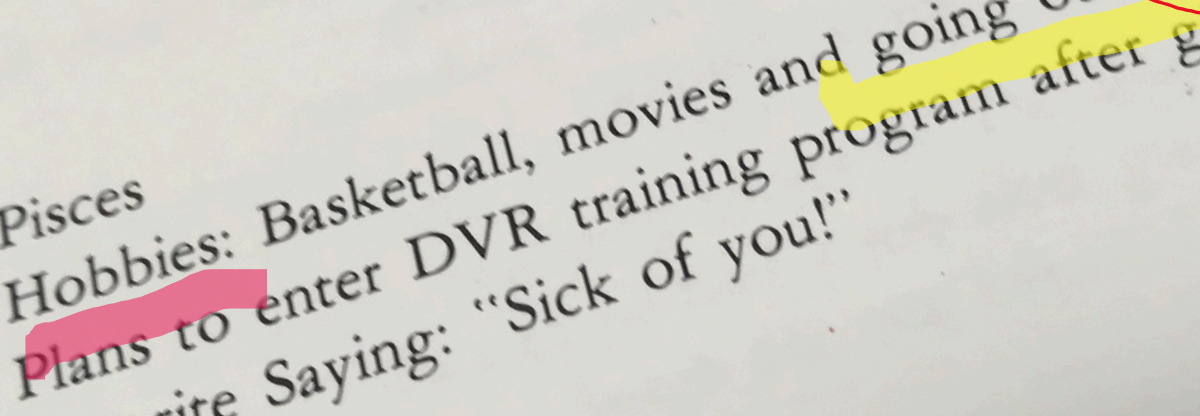
Favorite Saying:

22 


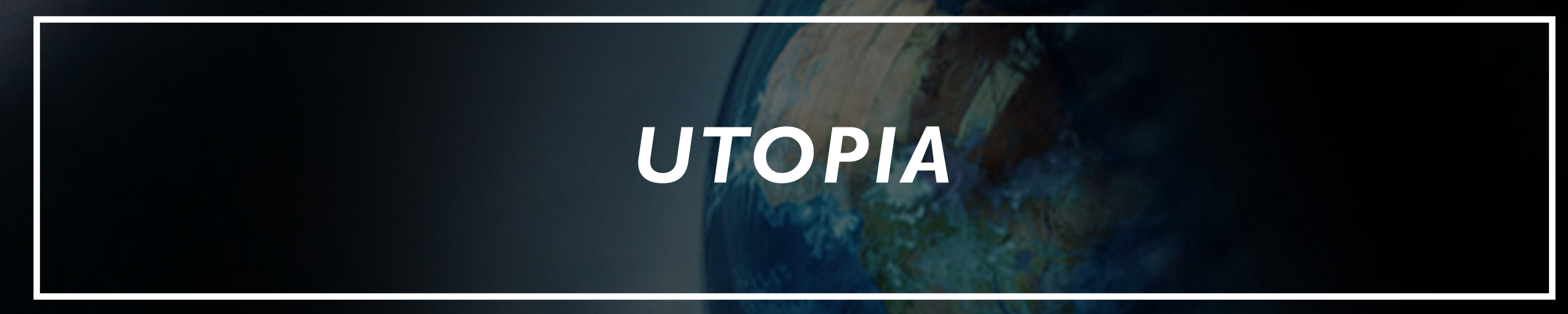


- Utopia [OED: 2. A place, state, or condition ideally perfect in respect of politics, laws, customs, and conditions]

UTOPIA

- Why Utopia? The benefits of this search looks at how a community imagines an ideal world free of dogmatism. 


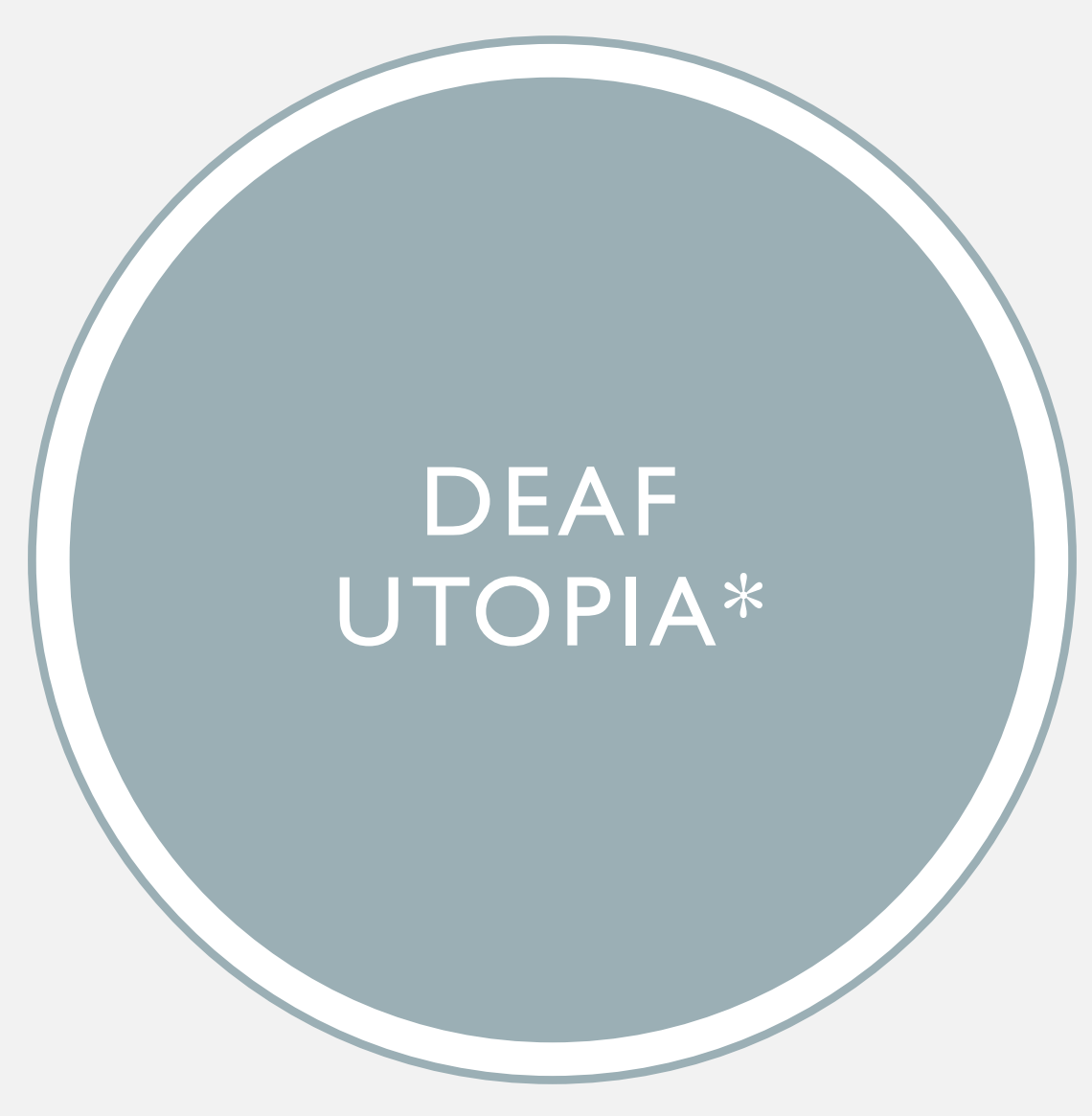

- Pursuit of a Deaf state/town/place

- J.J. Flournoy (I855)

- Jane Elizabeth Groom (I880)

- Marvin Miller (2004-2006)

- And others 


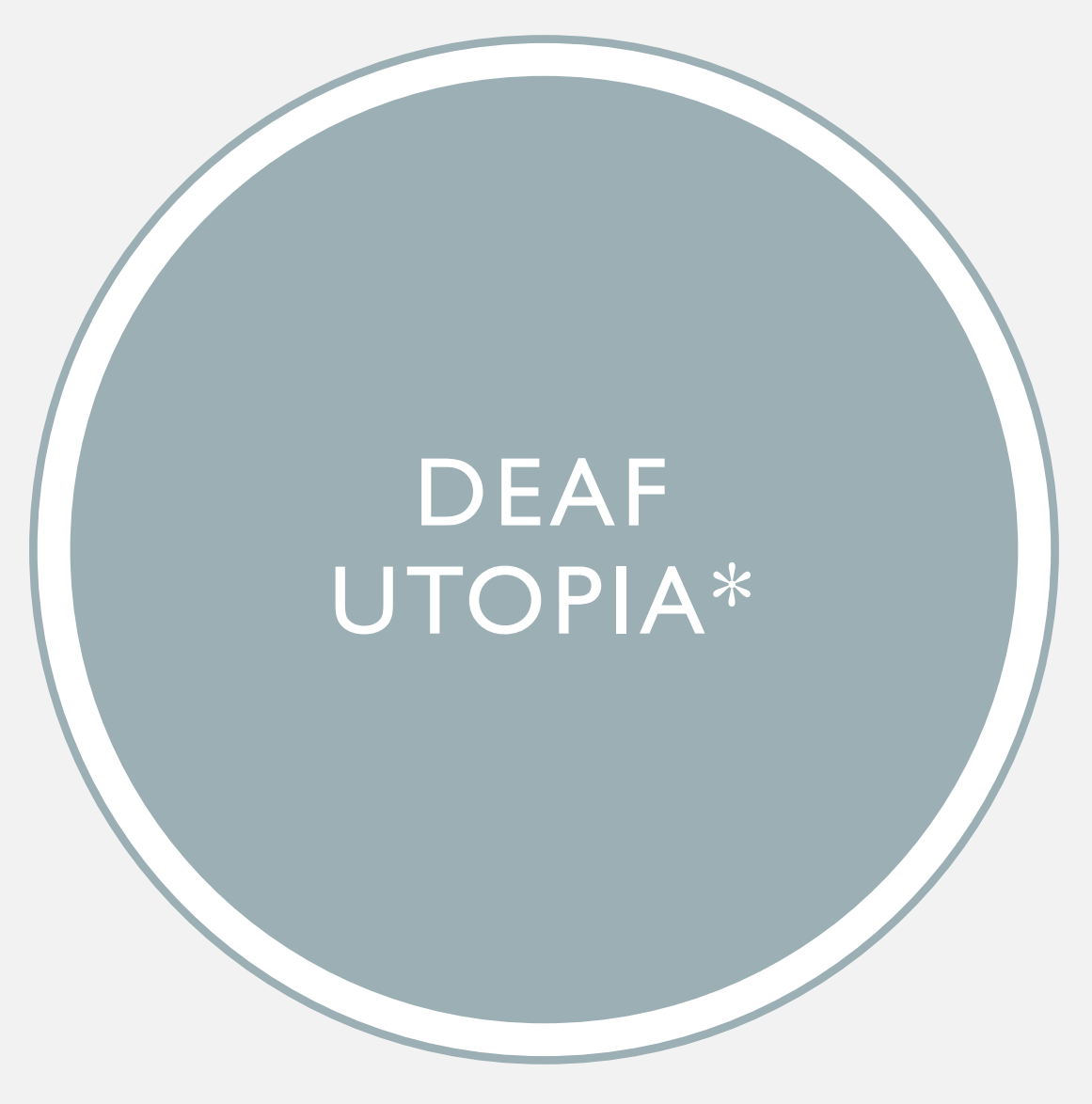

- Literature

- Islay by Douglas Bullard

- Eyeth

- Underlying theme:

- Paradigm shift: communication is not an issue

- Freedom from communication inequality.

- Superheroes

- Sign Gene

- The Fingerspellers

- Theme - Power of signing 


\section{UNIFYING THE DATA}

- Communication and Language Values

- Sign Language as Human Rights

- Bilingualism

- Access to Quality Information

- Fighting Oralism

- Access

- Dealing with Ignorance and Discrimination

- Audism

- Stigma

- Driving

- Mainstreaming and isolation as best practice

- Sensory Orientation and Sensory Worlds

- Visual-tactile orientation 


\section{COMMUNICATION}

- The three general themes listed in the prior slide

I. Communication and Language Values

2. Dealing with Ignorance and Discrimination

3. Sensory Orientation and Sensory Worlds

- The themes boil down to issues of communication.

- So... our data points to different communication issues and practices when it comes to Deaf people 
BEGGING FOR A BITE BY

ERIC EPSTEIN

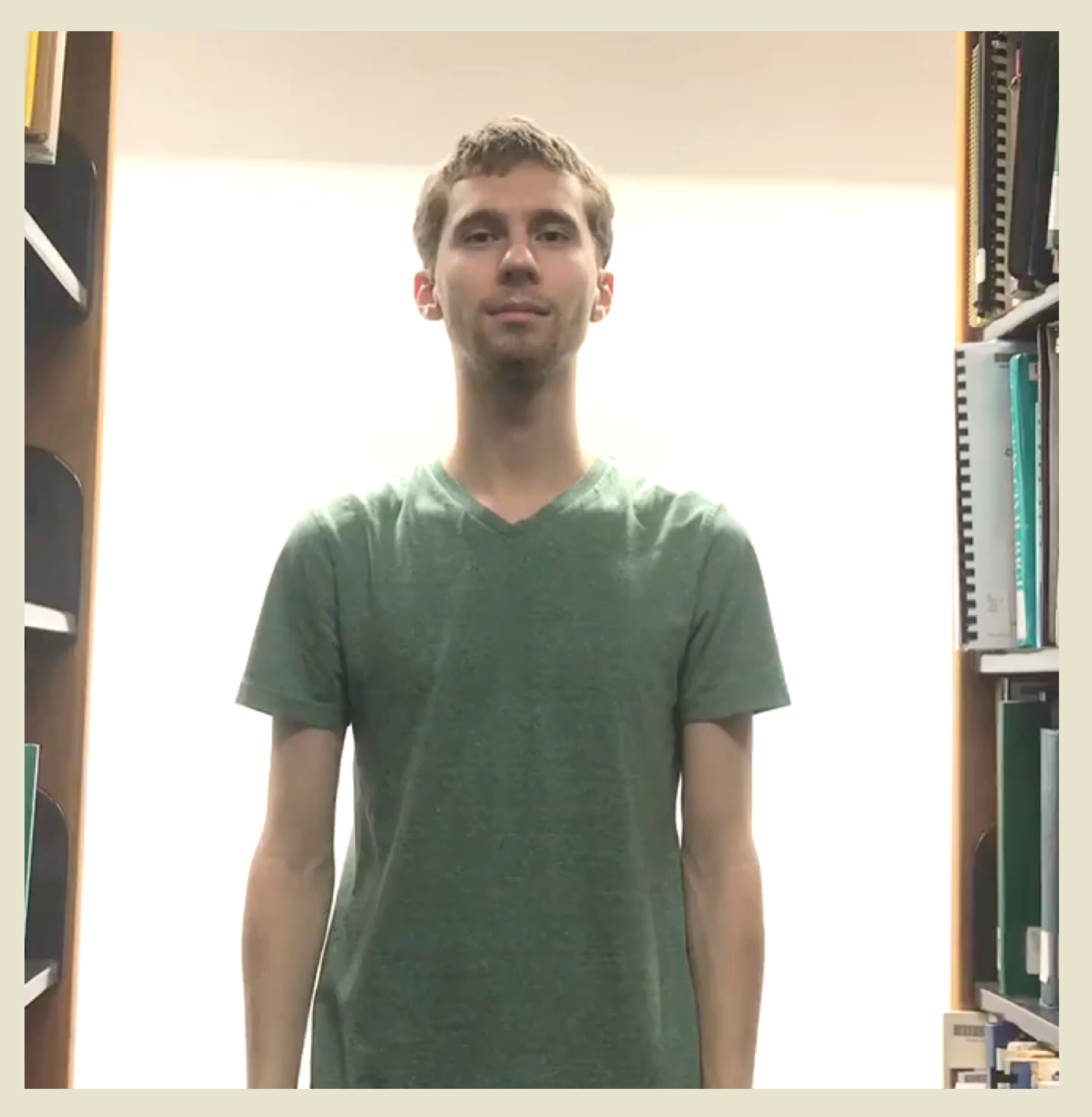




\section{COMMON GROUND}

- "The ability to create common conceptual ground-joint attention, shared experience, common cultural knowledge-is an absolutely critical dimension of all human communication (Tomasello, 2008, p.5)." 


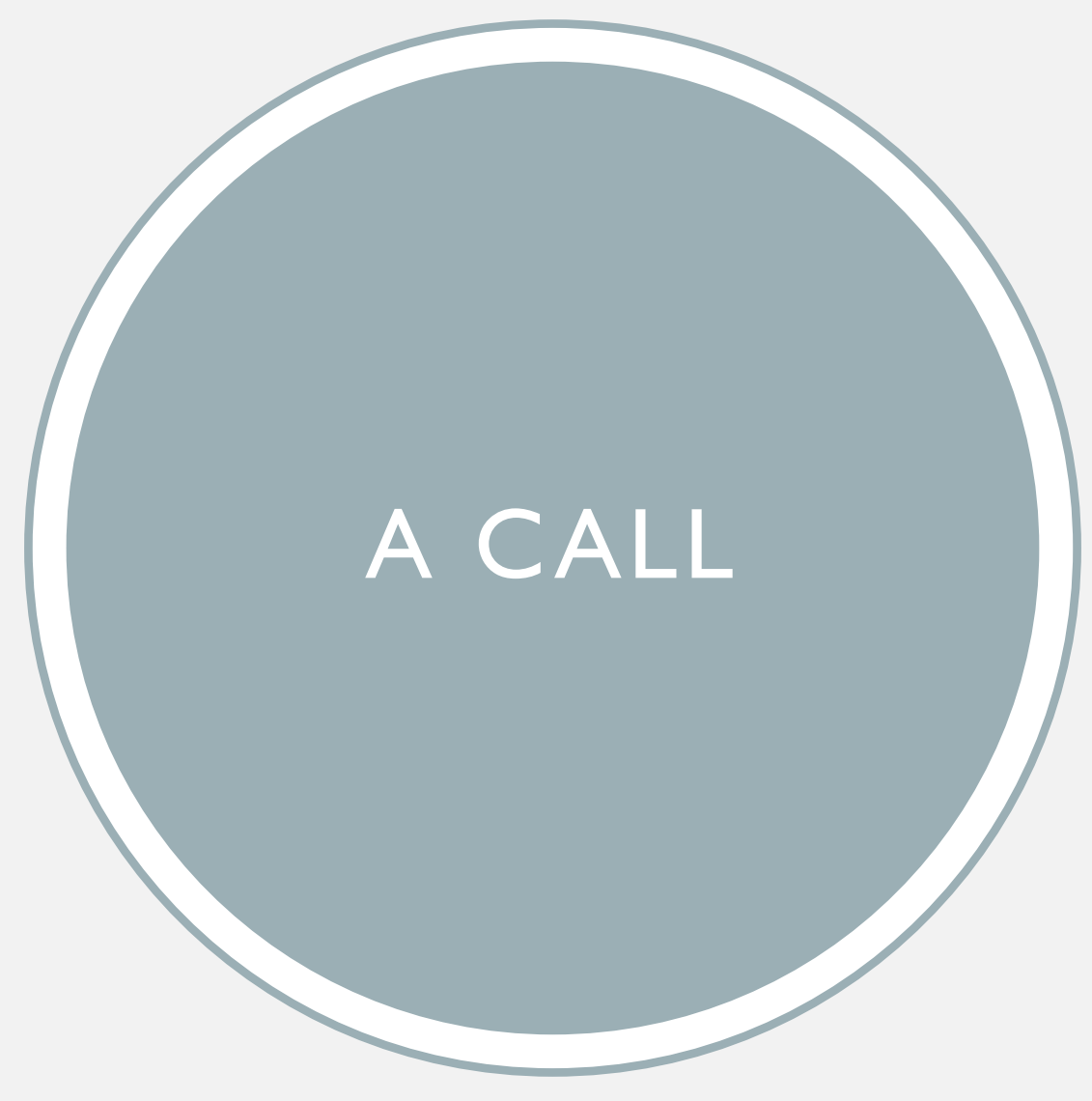

- The theme of communication is NOT new.

- It is so OBVIOUS.

- We have been saying that all over and everywhere.

- Now our task is to form a theoretical statement that becomes our "Theory of "Everything" for Deaf Lives"

- A theory that can then be used to gauge society at large. Using the theoretical lens to examine literature like "The Great Gatsby" 


\section{OUR TASK BEGINS}

Thank you 